\title{
Lock-in Analysis on Risk-taking by the Third-party Education Evaluation Agencies
}

\author{
Yang Chun Sun, Yao Zhang \\ Graduate School of Education, Dalian University of Technology, Dalian, China \\ Email address: \\ sunyangchun2003@163.com (Yang Chun Sun), 893942816@qq.com (Yao Zhang)
}

\section{To cite this article:}

Yang Chun Sun, Yao Zhang. Lock-in Analysis on Risk-taking by the Third-party Education Evaluation Agencies. Science Journal of Education. Vol. 7, No. 5, 2019, pp. 101-106. doi: 10.11648/j.sjedu.20190705.11

Received: September 17, 2019; Accepted: September 30, 2019; Published: October 15, 2019

\begin{abstract}
The "moral hazard" of the third-party education evaluation agencies has drawn extensive attention under the separation system of supervision, running and evaluation. The emergence of "moral hazard" is bound to be accompanied by other risks. In fact, the third-party education evaluation agencies will "transfer" risks to the government in order to protect their own interests in the education evaluation. If the risks are solely taken by the government for a long period, the evaluation system will not work well. Introducing the "lock-in" in economics into education field, this paper attempts to clarify the reasons of the third-party education evaluation agencies locking the government and the reasons why the government is willing to be locked by the third-party education evaluation agencies. By using critical discourse analysis, this paper shows that costs and cognitive limitations are the main reasons for lock-in. Accordingly, measures are put forward from the third-party education evaluation agencies and the government, which, to a certain extent, can reduce the degree to which the government is locked in by the third-party education evaluation agencies in order to promote the education evaluation work. This paper is of great significance in laying a solid foundation for further research on how to avoid the "moral hazard" of the third-party education evaluation agencies in the future.
\end{abstract}

Keywords: The Third-party Education Evaluation Agencies, Risks, Lock-in

\section{Introduction}

The term "risk sharing" has become a consensus concept in institutional economics, and neither party can "shirk" or "transfer" the risk responsibility. However, the issue that the third-party education evaluation agencies often "transfer" risks to the government in the field of education has received considerable critical attention. The "transfer" will produce a "lock-in" effect. Lonsdale, a foreign scholar, defines a state of lock-in that often occurs in public-private partnerships. "In public-private partnerships, it is common for the private sector to transfer the public sector's risks to the public sector by locking the public sector." [1] The "transfer" of risks from the third-party education evaluation agencies to the government will not only reduce the efficiency of risks management, but also bring greater risks to the government in the long term. This article attempts to show that the Lock-in Theory provides a useful account of clarifying the locking relationship between the third-party education evaluation agencies and the government, and finds the measures of unlocking. Clarifying the locking relationship between the third-party education evaluation agencies and the government will help the former to give up locking the latter and consciously share the risks with the government.

In recent years, there has been an increased number in higher education evaluation agencies, which has changed the form that education quality was previously evaluated by the government alone. The emergence and development of the third-party education evaluation agencies have made the evaluation of education more professional, but at the same time the government-led evaluation model still exerts great influence. In other words, the government has been thought of as a key factor in the history of development education evaluation. At present, most of the third-party education evaluation agencies appear as agents in the evaluation work. Previous studies have discussed the relationships between the third-party education evaluation agencies and the government. As JIANG states, "there are still some problems to be solved in the third-party agencies, for instance, lacking of subjectivity" [2]. Under the influence of centralization, 
the "government's official-oriented thinking of 'taking the overall situation as a whole' makes the administrative dependence of the third-party agencies too strong and their independence weak" [3]. The dependence on the government has also become a stumbling block for the development of the third-party evaluation agencies, "the education evaluation agencies are usually positioned as the direct institutions for education evaluation in the education departments of governments at all levels and are under the overall supervision of the government" [4]. The fact that the third-party education evaluation agencies are too dependent on the government and lack relative independence, which "forms a lot of parasitic organizations that rely on the power of the government" [5]. The shortcoming of too much reliance on government leads these parasitic agencies to "lack independence and intermediary, and it is difficult to achieve effective coordination among universities, governments and markets" [6]. WANG concluded that "strong administrative dependence and poor independence are common problems in higher education evaluation agencies in China" [7]. In addition, the imperfection of internal operating mechanism leads to "the unclear responsibilities, rights and interests of education intermediary agencies and the unclear definition of their relationship with the government. In the process of participating in educational governance, they often show a wavering state, and even lead to conflicts and contradictions between them and the government and other governing bodies" [8].

Considering all of these evidence, it seems that third-party education evaluation agencies are too "reliance" rather than "dependent" on the government in the education evaluation. As far as the government is concerned, "it is often accustomed to controlling and supervising educational activities through power and orders" [9]. On this basis, the study further proposes that the third-party education evaluation agencies gradually produce an inertia: "transfer" risks. The overarching questions of this paper are as follows:

1. What is the lock-in phenomenon in the education evaluation?

2. Why do the third-party education evaluation agencies lock the government and why does the government is willing to be locked by the third-party education evaluation agencies?

3. How can the government break the lock by the third-party education evaluation agencies?

\section{What Is the "Lock-in" Theory}

In 1989, Arthur W. B proposed the term "Lock-in" [10] to analyze the technological competition in the market. The main representatives are Arthur, North, Krugman, etc. Lock-in phenomenon, often appears in economics, usually refers to that the subject is affected by previous decisions when making decisions. Currently, Lock-in Theory has been widely used in technological innovation, value networks, industrial upgrading and other fields. In this study, the term will be used to describe relationship between the third-party education evaluation agencies and the government.

The arise of Lock-in is essentially path dependent. "The development of things has a dependence on the choice of roads and rules. Once a certain path is chosen and the rules of conduct are formed, it is difficult to change." [11] In an attempt to gain benefit as much as possible, the third-party education evaluation agencies "transfer" risks to the government. The government will take the initiative to take risks in order to maintain the cooperative relationship between the two parties. "As time goes by and resources are invested, agencies are becoming more accustomed to the past cooperation models, and their aversion to change is gradually increasing" [12]. This path dependence enables the third-party education evaluation agencies to "lock" the government without taking risks, and to continue along the path of the past. The efficiency of risk management will be low when the risks are completely taken by the government, finally, it will inevitably form a vicious circle. Lock-in phenomenon is usually manifested that the third-party education evaluation agencies lock the government and the government passively accepts the lock of the third-party education evaluation agencies.

The third-party education evaluation agencies lock the government in three aspects in the education evaluation.

First, the third-party education evaluation agencies lock the government-led institutional norms. In the evaluation work, the third-party education evaluation agencies rely too much on government-led risk regulation and system construction, and lack independence. China's education evaluation system is imperfect and the government-led education evaluation system is deeply rooted traditionally, which results in that the development of the third-party education evaluation agencies are not mature enough to be completely out of government guidance and be more dependent on the policies formulated by the government to survive.

Second, the third-party education evaluation agencies lock the government to undertake the cost of risks. For the purpose of economic benefit, the third-party education evaluation agencies are not willing to take risks. There will be some uncertainties, because the education evaluation duration is very long and the process is very complex. Obviously, the third-party education evaluation agencies choose to "transfer" risks to the government when risks are generated by these uncertain factors. Under this circumstance, the government can bear the cost of dealing with the risks.

Third, the third-party education evaluation agencies lock the government to deal with the consequences of risks. The emergence of risks will inevitably lead to a series of consequences, such as a decline in reputation. The third-party education evaluation agencies do not have to take risks or concern about reputation decline in a state of lock-in. The reason is that in the traditional sense, problems arise because the entities who take risks are not performing well. This will exert negative impact on the government's reputation but has no effect on the third-party education evaluation agencies' reputation. 


\section{Why Do the Third-party Education Evaluation Agencies Lock the Government}

The fact that the third-party education evaluation agencies lock the government and "transfer" the risks to the government which harms the government's interests and the education evaluation system. Therefore, it is necessary to analyze the reasons of locking.

\subsection{Increasing-returns Mechanism}

Arthur believes that increasing returns is the economic root of path dependence in the process of technological change. Economist North argues that if a system chosen in the initial stage brings about an increase in returns, and this system will continue to be consolidated and improved afterwards. This is the positive feedback of path dependence. "Economic systems based on increasing returns follow the principle of positive feedback" [11].

At the beginning of the education evaluation work, the third-party education evaluation agencies "transfer" their risks to the government, and the government accepts risks in order to maintain the cooperative relationship between the two parties, which allows the third-party education evaluation agencies to not have to bear the risks of losses, but also continue to earn revenue. Once the model be well embedded in the whole model in the further development of the evaluation work, a "virtuous circle" will be generated to strengthen its position. As the number of uses of this model increases, so does the experience and the benefits gained by the third-party education evaluation agencies. Eventually, the third-party education evaluation agencies will lock the government to protect their own interests without taking risks and the consequences.

\subsection{Traditional Cognition Limitations}

The limitations of traditional cognition bring limitations in risk management. Compared with Western countries, China has a traditional administrative system, implementing a highly centralized planning system so that the idea of "all-powerful government" is deeply rooted traditionally. On the one hand, the government wants to manage everything; on the other hand, people are willing to rely on the government to take on everything. Without any exaggeration, the government has controlled all areas of society strictly. Recently, "the inertia of the political system cannot be ignored, and the government still has a 'huge' voice" [13] despite the growing voice of the government streamlining. Each entities influenced by this kind of thinking and social environment will intensify lock the government.

Due to the bounded rationality of people, it's not surprising that the third-party education evaluation agencies generate risks in the evaluation work. More importantly, the agencies believe that the government as the leader in charge of all should take these risks. This is an expression of over-reliance on the government and lacking of independence.
Correspondingly, the government also has the inertia of thinking that it has the ability and obligation to take risks. This gradually evolved into a "consensus group thinking" [14] that caused misjudgment of risk management and triggered a cognitive lock on the government by the third-party education evaluation agencies. Cognitive lock-in comes from ideas or opinions that are recognized in people's hearts and cannot be easily changed. In addition, it will only deepen the degree of locking of the third-party education evaluation agencies to the government over time.

\subsection{Risk-averse Effect}

People's current decisions may create risks in the future development of the education evaluation work. When risks arises, it is necessary to take risks. But in general, it seems that people are averse to risks because they have to pay a certain amount of cost. Therefore, the contract will be used to stipulate the penalty for breach of contract before the cooperation between two parties. "This kind of breach of contract punishment, which in turn causes the cost of switching behavior in the lock-in effect and exacerbates the lock-in effect." [15]

Because the government and the third-party education evaluation agencies are unpredictable about the future evaluation work, the first step should be to take the implementation regulations and the penalty for breach of contract in the contract into account in order to deal well with the risks that may arise later. When the third-party education evaluation agencies create risks in the evaluation work and violate a certain clause in the contract, it means that they must take risks and accept the penalty for breach of contract. The third-party education evaluation agencies "transfer" risks to the government in the event of having to accept penalties for breach of contract for the purpose of risk aversion as well as maximizing their own interests. This is an important reason for the third-party education evaluation agencies to firmly lock the government and "transfer" risks to the government.

\section{Why Is the Government Locked by the Third-party Education Evaluation Agencies}

It is no wonder that the third-party education evaluation agencies lock the government for profit-making purposes and "transfer" the risks to the government. What is surprising is that why does the government is willing to be locked by the third-party education evaluation agencies? There are three reasons why the government accept the lock-in: high sunk cost, high opportunity cost and high conversion cost.

\subsection{High Sunk Cost of Government Investment}

High sunk cost refers to the accumulation of resources embedded in a partnership. Both partners invest a certain amount of time, manpower and material resources in order to build the relationship. The reason why the sunk cost causes the 
lock-in is mainly because of the "non-recyclability" [16] of relational investment. Non-recyclability means that capital, manpower, material resources and other capital cannot be restored after being invested from one party to the other. Therefore, the party that invests in capital will pay special attention to the maintenance of the relationship, and will not easily disconnect the relationship with the other party.

As the principal, the government has to entrust the professional third-party education evaluation agencies to make the education evaluation work more effectively. When the partnership is established, the government has to spend a certain amount of capital in building and maintaining relationships with the third-party education evaluation agencies. The government has made it clear that the capital spent on the third-party education evaluation agencies cannot be recovered once it is put into it. When the government does not accept the risks "transferred" by the third-party education evaluation agencies, it will damage the cooperation between the two. The government is willing to accept and deal with these risks may be due to the relationship capital of the previous large investment. The third-party education evaluation agencies grasp the government's characteristics and lock the government. The more relational capital is invested, in other words, the higher the sunk cost, the deeper the government is locked.

\subsection{High Opportunity Cost of Government Investment}

High opportunity cost refers to the potential loss accumulated in a partnership, that is, the loss or reduction of future earnings. Both partners have long-term exchanges and investigations before selecting the other party, and feel that the other party can bring benefits to themselves. For example, if one party chooses the other party, a possible explanation for this might be that the other party has strong personal resources Through the network relationship of the other party, you can enjoy rich resources and potential future benefits. If the two cancel the partnership, it means that one party does not enjoy the resources brought by the other party. At the same time, it loses the possible future benefits. If the resources of the new partners are not as strong as those of the original partners, it means that a reduction in future earnings.

The government selects the third-party education evaluation agencies through strict indicators, such as the personnel qualifications of the agencies, the performances of the agencies, the management structures of the agencies and so on. These standards that the government places an emphasis on are the basis for long-term cooperation between the government and the third-party education evaluation agencies. And the performance of a well-established evaluation agency, such as the fairness of the evaluation results and social credibility, will bring current benefits and potential future benefits to the government. In the case where the performance of the third-party education evaluation agencies "transferring" risks to the government is satisfactory, if the government chooses to end this partnership, it will lose the income that the third-party education evaluation agencies may bring. The mature education evaluation agencies have the effect of increasing-returns, and the dissolution of the relationships means that the government needs to find new agents. The future earnings might decrease when new agents are not as good as previous agents. In short, at high opportunity cost, the government tend to accept the third-party education evaluation agencies' lock-in.

\subsection{High Conversion Cost of Government Investment}

High conversion cost is the various costs that a party pays when it leaves the other party. For example, "the customers is locked and it is difficult to transfer from one brand to another when there is a huge conversion cost" [17] in the process of consumption. In the bilateral cooperative relationship, it must re-find new partners in the market when one party wants to dissolve the cooperation relationship with the other party. Establishing a partnership with a new partner requires a new round of investment and a huge cost. At the same time, the resources of previous partners have also been lost, and new partners may not be able to bring the value generated by previous partners.

If the government does not satisfy the current third-party education evaluation agency that "transfers" risks to it, and replaces with a new agent, not only can the government's previous investment not be recovered, but also require a new round of investment for the new agent. This actually exists huge conversion cost. In fact, between taking the risks that the third-party education evaluation agencies "transfer" to themselves and finding new agents, the government is more inclined to accept these risks than spending more money, time, etc. in finding new partners. Therefore, it is so difficult to move from one agent to another that the government can easily be locked. And as the cost of conversion increases, the degree to which the government is locked will be deeper.

\section{Conclusion and Suggestion}

The existence of the lock-in creates a serious flaw in the handling of risks in education evaluation. In order to deal well with risks and promote the positive interaction between the third-party education evaluation agencies and the government, it is necessary to solve problem of the lock-in. The paper contributes to our understanding of lock-in and discusses the reasons for lock-in. Next, it will provide unlock paths from the third-party education evaluation agencies and the government.

\subsection{Suggestions for the Government}

Generally speaking, breaking the lock-in of the third-party education evaluation agencies on the government requires external forces to participate in it. This external force is the government. The government can play an important role in addressing the issue of lock-in, "and give full play to its 'control' ability in public governance of education by acting as a referee, formulating criteria and maintaining order" [18]. Therefore, the government needs to establish a risk-sharing mechanism and a benefit-sharing mechanism. 


\subsubsection{Establishing a Risk-sharing Mechanism}

The concept of risk-sharing is important to the education evaluation. The first step is that the government must establish the risk-sharing mechanism and clearly explain to the agents that the risks need to be shared in the education evaluation work. Next, it's necessary to develop a risk-sharing framework. The three stages of "preliminary sharing", "negotiating sharing" and "tracking and sharing" [19] of risks are defined, and the principle of risk-sharing is established. For some controllable risks, the government should clearly specify the subject of the risk-taking in the contract. For some uncontrollable risks, further allocation is required during the negotiation process. In addition, if the third-party education evaluation agencies do not deal well with the risks that it is supposed to take, the government needs to stipulate that it must accept certain penalties for breach of contract. Establishing a risk-sharing mechanism is to allow the third-party education evaluation agencies to take on their own corresponding risks by clarifying the subject of risk-taking instead of locking and transferring all risks to the government when risks occur. Establishing a risk-sharing mechanism and forcing the third-party education evaluation agencies to take risks will be more conducive to risk management and improve the quality of education evaluation.

\subsubsection{Establishing a Benefit-sharing Mechanism}

A benefit-sharing mechanism can motivate the third-party education evaluation agencies to take risks proactively. Taking risks is equivalent to paying costs. On the one hand, the third-party education evaluation agencies purse maximum benefits and lock the government when risks occur. On the other hand, if the third-party education evaluation agencies cannot obtain corresponding value returns based on superior resources, knowledge capabilities, and value created, they will reluctant to take risks. There is evidence that the government plays a crucial role in regulating risks. As the maker of institutional policies, the government needs to establish a benefit-sharing mechanism. The mechanism has a significant impact on the provision of certain compensation after the third-party education evaluation agencies take the corresponding risks. Risk-taking by the third-party education evaluation agencies means not only paying costs but also earning profits from taking risks. The reason is that, the distribution of benefits must be based on the contributions of the third-party education evaluation agencies. The more risks the third-party education evaluation agencies take, the more contributions they make, and the more benefits they naturally allocate. In addition, the third-party education evaluation agencies will obtain corresponding value returns based on their superior resources and efforts in the benefit-sharing mechanism. To a certain extent, it can increase the enthusiasm of the third-party education evaluation agencies to take risks. Therefore, a benefit-sharing mechanism can reduce the degree of locking of the third-party education evaluation agencies to the government.

\subsection{Suggestions for the Third-party Education Evaluation Agencies}

Lock-in has contributed to the decline in their own development. The third-party education evaluation agencies lock the government, which not only lost their independence in the market, but also damaged their reputation. Therefore, changing cognitive orientation and maintaining independence in the market are two significant contributory factors to the development of the third-party education evaluation agencies.

\subsubsection{Changing the Perception Orientation}

"As Stammer said, history affects the actor's beliefs, values, and preferences." [20] For a long time, the third-party education evaluation agencies have been accustomed to "transferring" risks to the government. However, they must adjust their own thinking and fully realize that locking in the government is not good for the development of themselves and the education evaluation system. Within the third-party education evaluation agencies, the first step is to make clear that no risks can be transferred to anyone when risks occur. Second, strengthening the training and education of internal evaluators is beneficial for risks management. Evaluators in training and education must realize that it is everyone's responsibility and obligation to take risks. Taking risks can cultivate employees' sense of responsibility and strengthen the cooperative relationship among employees, institutions and the government, lays a solid foundation for the development of education evaluation in the future. Finally, it is necessary to establish a risk-sharing concept within the agencies. As discussed above, the benefits are the greatest when the third-party education evaluation agencies share risks with the government. Changing cognitive orientation and no longer locking the government in cognition can effectively encourage the third-party evaluation agencies to take risks.

\subsubsection{Maintaining Relative Independence}

It is important to break the path dependence of third-party education evaluation agencies and to make them no longer lock the government. To fully consider the interests of various stakeholders in the education evaluation, it is necessary to empower the community to express more demands in the education evaluation system to overcome the influence of path dependence [21]. Therefore, the third-party education evaluation agencies must ensure that they are relatively independent in the market. When the third-party education evaluation agencies "transfer" risks to the government for the sake of benefit, it seems that they can enjoy more benefits without taking risks on the surface. From a deep point of view, however, it is difficult for the third-party education evaluation agencies to maintain their independence in the market. The government may also increase managements and restraints in helping the third-party education evaluation agencies deal with risks. The "official-oriented" thinking exerts a great influence on the Chinese and the government plays a great role in the evaluation of education, resulting in the third-party evaluation system of higher education in China is not perfect. For their long-term interests, the third-party education 
evaluation agencies must be more professional and independent in the evaluation market to obtain recognition from the public. However, the "transfer" of risks not only makes their relationship with the government more "close", but also damages the reputation in the hearts of the public. Thus, it is urgent that the third-party education evaluation agencies break the reliance on the government and maintain its relative independence.

In short, the third-party education evaluation agencies "transfer" risks to the government and have a great negative effect on the education evaluation work. Introducing the Lock-in Theory into the education evaluation, clarifying the reasons for the third-party education evaluation agencies to lock the government and finding out the paths of unlocking can promote the third-party education evaluation agencies to take risks. More importantly, it is of great significance to the development of the education evaluation system.

\section{Fund Project}

The National Social Science Foundation of China (BIA170163).

\section{References}

[1] Zheng Chen. Risk Distribution in Public-Private Sector Cooperation: Ideal, Reality and Enlightenment [J]. Journal of Public Administration, 2010, 3 (5): 183.

[2] Yan-Qiao JIANG. An Approach to a Ten Years' Accreditation Practice by Third Party for Sino Foreign Cooperation in Running Schools in Shanghai [J]. China Higher Education Research, 2017 (4): 82.

[3] Xing-Ming CHEN, Meng-Wei CHEN, Xuan LI. The Growth Path of Higher Education Third-Party Evaluation Organizations: In the Situation of the Separation of Management, Implementation and Assessment in China [J]. Forum on Contemporary Education, 2019 (4): 11.

[4] Lin-Li DAI. The legal "identity" of the UK Higher Education Quality Assurance Agency and its operation [J]. Fudan Education Forum, 2018, 16 (4): 112.

[5] Jia-Rong ZHOU, Hui-Qin LI. Separation of education management evaluation: substantive foundation, action logic and institutional barriers [J]. Journal of Higher Education, 2016, 37 (7): 17.

[6] Jun YAN, Xiao-Dong XU. Higher Education Governance and the Third Sector Organization-The improvement and development of the third sector organization in China's higher education governance [J]. Higher Education Exploration, 2015 (12): 14-15.

[7] De-Lin WANG. Actively promote the higher education evaluation system of public governance [J]. China Higher Education, 2016 (23): 56.
[8] Jie ZHANG. An Analysis of the Unbalanced Development of Educational Intermediary Organizations from the Perspective of Educational Governance [J]. Contemporary Education Sciences, 2016 (22): 26.

[9] Wen-Jie YANG, Guo-Rui FAN. The Reform of the Education Inspectorate System: 1977-2020: A Review of the Inspectorate Reform in China After the Introducing of the Reform and Opening-up Policy [J]. Research in Educational Development, 2017, 37 (21): 9.

[10] Arthur, W B. Competing Technologies, Increasing Returns, and Lock-in by Historical Events [J]. Economic Journal, 1989, 99 (3): 116-131.

[11] Zi-Long WANG, Xiao-Di XU. Locking and Unlocking Technology Innovation Path [J]. Science of Science and Management of S. \& T., 2012, 33 (4): 61.

[12] Qing-Hong MENG, Xiao-Tian DAI, Shi-Ming LI. A Review of Value Creation, Lock-in Effect and Their Relationship in Value Networks [J]. Management Review, 2011, 23 (12): 141.

[13] Yun-Yi TANG. Analysis of the "lock-in effect" in the management dilemma of non-governmental organizations outside China [J]. Journal of Social Sciences, 2012 (3): 81.

[14] Xiao-Feng LIU. Research on Path Dependence and Lock-in Effect of Financial Expenditure Mode of Higher Education in Geographical Regions [J]. Higher Education Exploration, 2016 (3): 20.

[15] Ming LI, Yun-Mei WANG, Chun-Lin SI. The Economic Nature and Cause of Lock-in Effect in Network Economy_-Based on the Perspective of Non-Transfer Cost [J]. Shanghai Management Science, 2009, 31 (5): 18.

[16] Parkhe, A. Strategic Alliance Structuring: A Game Theoretic and Transaction Cost Examination of Interfirm Cooperation [J]. Academy of Management Journal, 1993, 36 (4): 794-829.

[17] Ming LI, Yun-Mei WANG, Chun-Lin SI. How to Get Out of the Innovation Dilemma of Enterprises: An Analysis Based on Lock-in Effect $[\mathrm{J}]$. Science and Technology Management Research, 2010, 30 (11): 188.

[18] Ming-Ming MAO, Chong-Min LUO. Difficulties and Reconstruction Paths among Subject Relationships of Government Purchasing Educational Services in China [J]. Modern Education Management, 2016 (6): 6.

[19] Li-Hong LI, Bai-Feng ZHU, Ya-Chen LIU, Zhang Shu. Research on risk sharing mechanism under the overall framework of PPP model [J]. Construction Economy, 2014, 35 (9): 13.

[20] Xiang-Hua WANG, Xi-Lin ZHANG. The Difficulties and Countermeasures of the Third Party Evaluation of China's Higher Education from the Perspective of New Institutionalism [J]. Journal of Higher Education, 2018, 39 (6): 39.

[21] Zong-Xiang QU, Zhuo-Xuan WANG. On China's Higher Education Evaluation System from Perspective of Historical Institutionalism $[\mathrm{J}]$. Heilongjiang Researches on Higher Education, 2018, 36 (10): 60. 